
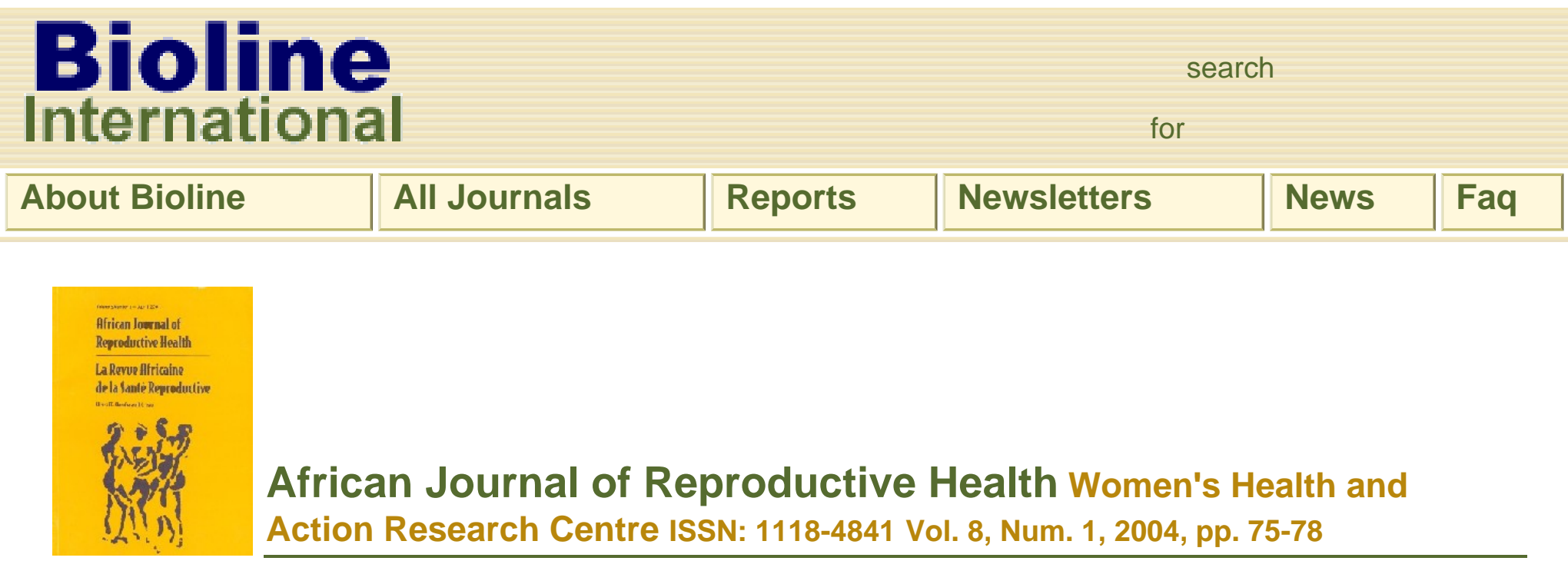

African Journal of Reproductive Health Women's Health and Action Research Centre ISSN: 1118-4841 Vol. 8, Num. 1, 2004, pp. 75-78

African Journal of Reproductive Health, Vol. 8, No. 1, April, 2004 pp. 75-78

\title{
Provision of Abortion Services by Midwives in Limpopo Province of South Africa
}

Mafanato Constance Sibuyi

Correspondence: Ms. Mafanato Constance Sibuyo, Department of Health and Welfare, Limpopo Province, Mkhensah Hospital, Main Street Giyami, South Africa. Tel: 27-51-8123251 ext. 2011 (Office), 27-83-9833442 (Cellular); Fax: 27-51-8122461; E- mail: bridget.holeni@dpe.gov.za

\section{Code Number: rh04013}

\section{Abstract}

South Africa's Choice on Termination of Pregnancy (CTOP) Act of 1996 allows provision of abortion on request up to 12 weeks of gestation and permits midwives who have completed required training to conduct termination of pregnancies. This unique codification of midwives' role in abortion care reflects legislators' recognition that the right to safe legal abortion would be meaningless to the vast majority of South African women who live in remote rural areas unless appropriate steps were taken to ensure their access to such services and an understanding that, by dint of their numbers and skills, this cadre of health care providers have much to offer. Though not without considerable challenges, experience from Limpopo Province demonstrates the important impact of involving midlevel providers has had in expanding the availability and accessibility of safe legal abortion. (Afr J Reprod Health 2004; 8[1]:75-78)

Key Words: Abortion, South Africa, CTOP Act, midwives, mid-level providers

\section{Résumé}




\section{Assurance des services d'avortement par des sages-femmes dans la province de} Limpopo, Afrique du Sud. L'Acte de 1996 en Afrique du Sud sur Le Choix d`Interruption Volontaire de la Grossesse (VIG) autorise l'avortement sur demande jusqu' à 12 semaines de gestation et permet aux sages-femmes qui ont suivi la formation requise d'entreprendre l'interruption de grossesses. Cette codification unique des rôles des sages-femmes dans le soin d`avortement montre que les parlementaires ont reconnu que le droit à l’avortement légal sans risque serait sans importance à la grande majorité des femmes sud-africaines qui vivent dans les régions rurales éloignées, sauf si des mesures appropriées sont prises pour assurer qu'elles ont accès à tels services. A force de leur nombre et leur compétence, le cadre des fournisseurs du soin de santé ont beaucoup à contribuer. Cependant, malgré les défis considérables, l'expérience tirée de la province de Limpopo démontre l`impact important que l`implication des fournisseurs intermédiaries a eu sur l’expansion de la disponibilité et à l’accès à l'avortement légal sans risque. (Rev Afr Santé Reprod 2004; 8[1]:75-78)

\section{Introduction}

The new South African constitution, adopted after the fall of apartheid, allows all citizens to exercise their right to choose on a number of important matters, enshrining freedom of religion, thought, belief and opinion. The constitution provided the foundation needed for passage of the Choice on Termination of Pregnancy (CTOP) Act No. 92 of 1996, which was promulgated in South Africa on October 31, 1996, and went into effect on February 1, 1997.

The act may be best known for allowing provision of abortion on request up to 12 weeks of gestation. Its biggest contribution to South Africa, however, may have been to allow midwives who had completed required training to conduct pregnancy termination. This article focuses on the important role of the midlevel provider in expanding women's access to safe abortion services, drawing on experience from Limpopo Province, South Africa.

\section{Emphasis on Access}

South Africa's CTOP Act is notable among abortion laws worldwide for the important prescient role it assigns to midwives. This unique codification of midwives' crucial responsibility in abortion care reflects the drafters', and South African legislators', recognition that the right to safe legal abortion would be meaningless to the vast majority of South African women unless appropriate steps were taken to ensure their access to such services.

The Act employs a three-pronged approach to termination of pregnancy, with different requirements for terminations performed in different stages of pregnancy. In the earliest stage up to and including the 12th week of pregnancy - it permits termination of pregnancy at the request of the pregnant client. The only consent that is required is that of the pregnant client herself. Given that such a large proportion of South African citizens live in remote rural areas, the Act stipulates that properly trained and registered midwives may perform terminations during this period.

From the 12th to the 20th week of pregnancy, a period in which the abortion procedure may be 
more difficult to perform and carry higher risks for the woman, termination must be conducted by a medical practitioner. Again, only the consent of the pregnant client is required.

After 20 weeks, termination may be conducted only under limited circumstances, and a second opinion from either a midwife or another medical practitioner is required. Midwives are centrally involved in counselling clients at all stages of pregnancy.

When we talk about freedom of choice and the CTOP Act, however, we must also recognise that doctors and nurses also have a choice. Conscientious objection to the CTOP Act is recognised, and both medical and nursing practitioners have the right not to provide abortion services if doing so would conflict with their personal beliefs.

\section{Why Midwives?}

South Africa's conscious decision to employ midwives to their fullest advantage in the provision of abortion care demonstrates an admirable understanding that by dint of their numbers and skills, this cadre of health care providers has much to offer. The database of the South African Nursing Council (the body that regulates the country's nurses) shows that there are more midwives than any other category of nursing practitioners in South Africa.

In addition, practicing midwives have a strong skills base which can easily be built upon to expand availability, accessibility and quality of abortion care. For example, they are very experienced in taking medical histories, performing physical examinations and counselling clients.

There are numerous other advantages to involving midwives more actively in abortion care, particularly in comparison to higher cadres of medical personnel, notably physicians. For instance, training midwives to provide more extensive care is more cost-effective and represents a solid life-long investment. In South Africa, most practicing midwives are females; female clients typically feel more comfortable with female providers, who can interact more empathetically with the client and her circumstances than male providers.

Importantly, midwives are usually based in the community and are more likely than centralised urban health care providers to understand and know the needs of the community. They are also the most accessible health care providers. Doctors on the other hand are spread very thinly in South Africa and tend to be concentrated in urban communities.

\section{Training}

South African legislators also recognised that it was not enough to simply authorise midwives to perform terminations of pregnancy. Careful preparation in the form of training was also necessary to enable the new law to be implemented effectively. 
termination of pregnancy using the manual vacuum aspiration technique of uterine evacuation. The curriculum has interim registration with the South African Qualifications Authority and has been registered with the South African Nursing Council as a short course.

From November 1998 to May 1999, RHRU conducted a national pilot training programme in which 83 volunteer midwives were trained to perform termination of pregnancy. Of the 83 who began the training, 73 midwives completed both the theoretical and practical components. On completion of the pilot project, the training was handed over to the provinces for the various provincial departments of health to manage, among which was Limpopo Province.

Since its programme began in 2000, Limpopo Province has trained 135 midwives to provide termination of pregnancy. The curriculum was slated to be adopted by the Limpopo Nursing College by the end of 2003.

\section{Service Delivery}

The South African Ministry of Health has designated 42 hospitals in the Limpopo Province as service delivery sites for termination of pregnancy. Service provision began in 1997, shortly after the Act went into effect. At that time, there were no trained midwives at the designated hospitals and the service was provided by medical doctors. In 1999 three hospitals began offering the service in four of the hospitals.

Between February 1997 and December 1998, when medical doctors were the only personnel performing terminations of pregnancy, Limpopo Province reported a total of 714 first trimester procedures. From January 1999 to December 2001, the number of first trimester procedures performed by midwives was 5,168 . Clearly, the availability of trained midwives had a dramatic impact on the availability of safe abortion procedures in the province.

To date (2003) 30 of the 42 hospitals are providing services, the remaining 12 will be on line by October 2003.

\section{Challenges}

Implementation of South Africa's CTOP Act has not been without challenges. Here, as in many other countries, provision of termination of pregnancy does not please all of the people all of the time. Pregnancy termination is a delicate sensitive issue fraught with political, religious and social implications.

Some South African midwives who have been involved in providing termination of pregnancy have found the challenges and obstacles they confronted insurmountable; many have in fact collapsed with stress and/or left the service. Even with a liberal supportive law, such challenges include: 
Bioline International Official Site (site up-dated regularly)

infrastructure, equipment, supplies and supervision.

- Negative attitudes of colleagues and members of the community, which has manifested as name-calling, harassment and intimidation.

- Inadequate training.

- Inaccessibility of second trimester terminations either because of lack of doctors in the community or available doctors' unwillingness to provide this service.

- Lack of knowledge within the community regarding the CTOP Act and the rights of women, and resulting frequency of women reporting to the clinic for terminations when they are 14-16 weeks pregnant - too late for the midwife to be able to perform the procedure.

\section{Lessons Learnt in the Decentralisation Process}

South Africa's experience with the CTOP Act to date offers numerous lessons that can help guide implementation of newly liberalised laws in other countries. For example:

- Properly trained and registered midwives can provide high quality abortion care services. These practitioners are more accessible and in some cases more acceptable to clients and the community than medical doctors.

- It is important to inform women of their rights under the law and the limitations on those rights. Community education about the law is also important.

- Values - clarification workshops are necessary and useful in offsetting negative attitudes and beliefs concerning termination of pregnancy before the service is implemented in an institution. All health workers and relevant community members should attend.

- Community education activities should be run in parallel to these workshops so that the correct information reaches the correct people. Women seeking the service should be encouraged to attend the clinic as early as possible so as to avoid the tragedy of having to send a woman to another institution, which may or may not offer second trimester services because she failed to come before 12 weeks.

- Support systems should be provided for health care workers.

- Continuous monitoring of services, evaluation quality of care, accessibility of services, support of health workers and supply of equipment are also necessary to prevent unsafe abortion services.

(C) Women's Health and Action Research Centre 2004 
Bioline International Official Site (site up-dated regularly)

Home Resources

Email Bioline

(c) Bioline International, 1989 - 2004, Site last up-dated on 20-Jan-2005. 